\title{
O PAPEL DO TUTOR: A EXPERIÊNCIA DA TUTORIA NO CURSO SEMIPRESENCIAL DA PEDAGOGIA UNESP/UNIVESP
}

\author{
Mauricio de Sousa \\ sousama@ig.com.br
}

\section{Resumo}

Este artigo descreve a atuação do tutor, chamado de Orientador de Disciplina, no curso semipresencial de Pedagogia promovido pela UNESP em parceria com a UNIVESP durante o período de 2010 a 2013. Além da descrição das atividades desenvolvidas pelo tutor, busca analisar a importância deste ator no desenvolvimento das ações pedagógicas em um curso na modalidade à distância.

Palavras chaves - educação a distância - tutor - ação pedagógica.

\begin{abstract}
This article describes the role of the tutor, called Discipline Advisor, in the pedagogy blended course offered by UNESP in partnership with UNIVESP, during the period from 2010 to 2013. Besides the description of the activities performed by the tutor, it seeks to analyze the importance of this actor in the development of pedagogical actions in a course at distance mode.
\end{abstract}

Keywords - distance education - tutor - pedagogical action.

\section{Resumen}

En este artículo se describe el papel del tutor, llamado Disciplina Asesor, en el curso de pedagogía blended promovido por la UNESP en colaboración con Univesp durante el período 2010-2013. Además de la descripción de las actividades realizadas por el tutor es analizar la importancia de este actor en el desarrollo de acciones pedagógicas en un curso en la modalidad a distancia.

Palabras clave - la educación a distancia - tutor - acción pedagógica.

\section{Introdução}

A Educação a distância (EAD) tem avançado sistematicamente na última década (RIGHETTI, 2013). A EAD não é nenhuma novidade já existe há muito tempo conforme descrito em Preti: 
experiências educativas a distância já existiram no final do século XVIII, desenvolveram-se com o êxito a partir da segunda metade do século XIX, para qualificação e especialização de mão de obra em face das novas demandas da nascente industrialização, da mecanização e divisão dos processos de trabalho (PRETI, 1996: 17)

Uma das primeiras experiências nesta modalidade de ensino, foi o uso de correspondência para o ensino de línguas na Europa. Mais precisamente, em 1840, na Inglaterra iniciou-se o ensino de estenografia, difundido pelo seu inventor Isaac Pitmam.

Os cursos na modalidade EAD abrangem desde o primeiro grau até a pósgraduação, atingindo mais de 80 países no mundo. Esta educação está voltada tanto para uma formação inicial, como continuada. (PRETI, 1996)

No Brasil, a EAD também remonta o início do século XX, com os cursos profissionalizantes realizados por correspondência, oferecidos pelas Escolas Internacionais. Outra experiência com educação a distância, foi o Movimento de Educação de Base que procurou através da utilização de programas radiofônicos, alfabetizar milhares de jovens, em especial, no Norte e Nordeste do Brasil (SANTOS, 2008).

Com a criação em 1996, da Secretaria de Educação a Distância, pelo Ministério da Educação e Cultura (MEC), a EAD se expandiu significativamente no país. Um dos programas em que esta Secretaria tem investido são os cursos oferecidos pela Universidade Aberta do Brasil (UAB), cursos estes de formação inicial e continuada, nas modalidades de graduação e pós-graduação. O sistema UAB, tem desde a sua criação, tido um grande avanço, conforme demonstra os dados da Secretaria de Educação a Distância:

Atualmente, 88 instituições integram o Sistema UAB, entre universidades federais, universidades
estaduais e Institutos Federais de Educação, Ciência e Tecnologia (IFETs). De 2007 a julho de
2009 , foram aprovados e instalados 557 polos de apoio presencial com 187.154 vagas criadas. A
UAB, ademais, em agosto de 2009 , selecionou mais 163 novos polos, no âmbito do Plano de
Ações Articuladas, para equacionar a demanda e a oferta de formação de professores na rede
pública da educação básica, ampliando a rede para um total de 720 polos. Para 2010, espera-se a
criação de cerca de 200 polo. (UAB, 2013)

Além da UAB, o MEC também tem investido, desde 2011, em cursos de formação técnica, em parceira com as escolas técnicas federais, denominada PRONATEC (Programa Nacional de Acesso ao Ensino Técnico e Emprego) que tem garantido a expansão do ensino profissionalizante.

A despeito desse quadro de plena expansão da educação a distância na primeira década do século XXI, muitas críticas ainda são postas a esta modalidade de ensino. Schlosser descreve muito bem o conjunto destas críticas: 
No entanto, mesmo com a legalidade e a supervisão das autoridades governamentais e dos esforços de várias instituições, ainda existe resistência e questionamentos quanto à qualidade do ensino a distância, a aceitação de diplomas dessa modalidade no mercado de trabalho e à desistência ou abandono da continuidade dos estudos de alguns alunos matriculados, de quem são exigidos disciplina e organização do tempo dedicado ao estudo. Além desses fatores que ameaçam a popularização da EAD, existe ainda as dificuldades por parte de alguns estudantes em lidar com as novas tecnologias e o analfabetismo virtual. (SCHLOSSER, 201, pág.5 )

Assim entendemos que a EAD atualmente passa por um processo não apenas de expansão, mas também de afirmação da sua qualidade de ensino. Acreditamos que da mesma forma que existem excelentes cursos presenciais, a EAD também tem cursos na mesma direção. Isto significa dizer que não é apenas a presença do aluno que garante a qualidade do ensino. Outros fatores, como formação dos professores, materiais utilizados, discussões, processo avaliativos e que podem garantir ou não a qualidade do ensino.

Dessa forma, este artigo pretende descrever a experiência da atuação do tutor na condução do processo de ensino e aprendizagem do curso de Pedagogia semipresencial promovido pela UNESP/UNIVESP, durante o período de 2010 a 2013. Esse curso não apenas buscou a expansão da formação continuada do professor, mas também demonstrou que uma educação de qualidade pode ser realizada a distância.

\section{O curso de Pedagogia semipresencial}

O curso semipresencial de Pedagogia originou-se a partir de uma parceria entre a UNESP e o Governo do Estado de São Paulo, através de um convênio com a UNIVESP (Universidade Virtual do Estado de São Paulo). Para a efetivação do curso ocorreu o envolvimento do Núcleo de Educação a Distância (Nead) da UNESP e a Fundação Padre Anchieta, através do canal, TV UNIVESP, para a produção de vídeos relativos ao curso de Pedagogia.

O público alvo desse curso eram professores que atuavam em sala de aula na educação básica. Em decorrência disso, o conjunto de alunos aprovados no vestibular formouse um grupo de: licenciados e, outro de alunos que não tinham a formação superior. Com isto, podemos afirmar que este curso de Graduação em Pedagogia, tratava também de uma formação continuada do professor. 
A organização estrutural do curso semipresencial de Pedagogia era composta por polos presenciais nas cidades em que a UNESP possuía um campi, ou seja, vinte uma 21 cidades, acolhendo 27 turmas. Em cada polo havia uma turma de 50 alunos; em algumas cidades existiam duas turmas (Bauru, Guaratinguetá, São Vicente); apenas na cidade de São Paulo foram compostas quatro turmas: três turmas localizadas no Instituto de Artes da UNESP e uma turma na sede do Núcleo de Educação a Distância da UNESP.

Cada grupo tinha dois Orientadores de Turma, professores efetivos da UNESP. Inicialmente havia apenas a atuação de um Orientador de Turma, posteriormente para a orientação dos Trabalhos de Conclusão de Curso (TCC) e dos estágios supervisionados, fezse necessário a atuação de dois Orientadores de Turma. Todos os Orientadores de Turma, além de serem efetivos da UNESP, tinham o título de Doutor. Estes orientadores de turma, quinzenalmente, participavam das atividades presenciais desenvolvidas no polo e posteriormente passaram a atuar na orientação dos estágios e TCC.

Para o desenvolvimento das atividades propostas pelo curso, havia os Orientadores de Disciplina (tutores). Estes Orientadores de Disciplina foram contratados através de concurso público, todos tinham formação em Pedagogia ou licenciatura, e a grande maioria possuía pós-graduação stricto sensu, Mestrado ou Doutorado. A carga de trabalho era de 20 horas semanais, e como principais funções, tinham que desenvolver as atividades propostas nos Cadernos de Formação durante os encontros presenciais (sempre às segundas e quintas-feiras), corrigir as atividades dos alunos postadas na plataforma, aplicar provas e realizar a sua correção. Ou seja, o contato direto com os alunos presencialmente e virtualmente, era quase que exclusivamente de responsabilidade do Orientador de Disciplina.

Para o desenvolvimento das suas atividades os Orientadores de Turma e Disciplina, eram capacitados, pelo período de aproximadamente 16 horas, a cada nova disciplina adicionada ao curso. Ao todo foram 30 disciplinas e consequentemente ocorreram quase trinta encontros entre Professores Autores dos cadernos de formação e Orientadores de Turma e Disciplina. Nestes encontros eram apresentados os objetivos das disciplinas, os textos que seriam trabalhados e as atividades a serem desenvolvidas.

Estes Orientadores de Disciplina ficaram responsáveis por acompanhar o desenvolvimento de 25 alunos, em cada turma. Entretanto, na prática esta divisão acabou não 
ocorrendo, pois os orientadores atuavam juntos no desenvolvimento de todas as atividades pedagógicas. Com isso todo o processo pedagógico dos encontros presencias, a aplicação de provas e correção das atividades, foi desenvolvido conjuntamente.

Na composição da estrutura pedagógica do curso de Pedagogia semipresencial havia também o Professor Autor das disciplinas, que poderia ser também um Orientador de Turma. Cada professor autor foi responsável pela organização dos textos que comporiam a sua disciplina. Muitos professores autores escreveram todo o caderno, e outros, selecionaram textos de diferentes autores para composição deste caderno de formação. Além da produção dos cadernos de formação, o professor autor era responsável pela a elaboração das atividades que seriam desenvolvidas ao longo de sua disciplina. Estas atividades eram constituídas de questões dissertativas sobre os textos, fóruns de discussão entre os alunos, questões objetivas, produção de materiais pedagógicos, pesquisa no contexto escolar, etc.

Por fim, o Professor Autor, realizava a capacitação dos orientadores e ficava disponível virtualmente no Ambiente Virtual de Aprendizagem (AVA), em um espaço chamado Equipe, para esclarecer dúvidas e orientar as atividades.

Pensando em uma estrutura organizacional hierárquica podemos dizer que dois núcleos centrais organizaram todo o curso. O primeiro era a Coordenação Pedagógica, responsável pelo desenvolvimento de todo o projeto pedagógico do curso; como funções podemos elencar: a organização da grade curricular do curso, a indicação dos professores autores dos cadernos de formação, o acompanhamento do processo pedagógico, a orientação das formações dos orientadores, etc. Na mesma posição, havia a Coordenação de Mídias, responsável pela efetivação dos materiais no Ambiente Virtual de Aprendizagem (AVA) de todo o curso. Ou seja, todo o projeto pedagógico do curso tinha que ser organizado e pensado dentro das possibilidades do AVA, assim as atividades, textos para discussão, vídeos, publicação de notas das avaliações, etc. eram analisados e revistos pela Coordenação de Mídias.

Com relação a organização da grade curricular, o curso semipresencial de Pedagogia foi organizado em 30 disciplinas, dividas em três grandes blocos de conteúdos, conforme descreve o Manual Acadêmico do Aluno: 
O Curso de Pedagogia do Programa UNE SP/UNIVE SP está organizado em 3 Blocos, sendo que o primeiro deles é constituído de 3 Módulos e os dois últimos Blocos de um único Módulo. Cada um dos Módulos, por sua vez, está organizado por Disciplinas. Os módulos integram-se por eixos articuladores.

Os Eixos Articuladores devem ser entendidos como centros geradores a partir dos quais são trabalhadas as teorias e as práticas educativas de conformidade com as Disciplinas.

O número de horas a serem integralizadas no curso é de 3.480 h (três mil, quatrocentas e oitenta horas), sendo 2970 de Atividades Formativas, 300 horas de Estágio Supervisionado e 210 horas de Trabalho de Conclusão de Curso. As 2970 h de atividades formativas serão desenvolvidas em três blocos:

Bloco 1 - Formação Geral - 1050 horas

Bloco 2 - Didática dos Conteúdos - 1440 horas

Bloco 3 - Gestão Escolar - 480 horas

Eixo articulador do Bloco 1

Memória do Professor - 90 horas

Eixo articulador do Bloco 2

Educação Inclusiva e Especial - 120 horas (UNESP/UNIVESP, 2010, págs. 20-21)

Podemos perceber que a grade curricular procura dar uma visão geral das disciplinas de formação básica do profissional professor com disciplinas como: (Educação e Sociedade, Ética e Cidadania, Política Educacional, Filosofia da Educação, Sociologia da Educação, etc.) para em seguida, pensar todos os conteúdos didáticos que são desenvolvidos na educação infantil e nas séries iniciais $\left(1^{\circ}\right.$ ao $5^{\circ}$ ano $)$ do ensino fundamental desde a alfabetização, passando por todos os conteúdos didáticos como: História, Geografia, Ciências, Língua Portuguesa, etc. Por fim, o último bloco formado por disciplinas voltadas para gestão escolar. Perpassando todas estas disciplinas havia dois eixos articuladores, que buscavam relacionar os conteúdos aprendidos em cada área do conhecimento com um eixo articulador: primeiramente, Memória do Professor e depois Educação Inclusiva. O objetivo destas disciplinas era pensar uma transdisciplinaridade no próprio curso de Pedagogia.

Por fim, o desenvolvimento de todas as atividades pelos cursistas foi dividido na seguinte carga horária:

O Curso de Pedagogia UNE SP/UNIVE SP tem um total de 3.480 horas de duração, das quais 2.970 horas respondem pelos conteúdos de formação, às quais se acrescentam 300 (trezentas) horas de Estágio Curricular Supervisionado e 210 (duzentas e dez) horas referentes ao Trabalho de Conclusão de Curso. No cumprimento dessa carga horária, haverá atividades presenciais (40\%) e não presenciais (60\%), com momentos síncronos e assíncronos, ao longo de 7 semestres letivos. (UNESP/UNIVESP, 2010, págs. 20-21)

Ou seja, nesta modalidade de ensino semipresencial, a presença do aluno era obrigatória em $75 \%$ dos encontros presenciais, que totalizava $40 \%$ de toda a carga horária do 
curso. Cabe ressaltar que não era previsto dependência em nenhuma disciplina. Assim se o aluno ficasse reprovado na disciplina, automaticamente seria desligado do curso.

Podemos perceber por esta breve descrição do curso semipresencial de Pedagogia promovido pela UNESP e em parceria com UNIVESP, que existem muitas diferenças em relação aos cursos totalmente a distância, em especial quando comparado aos cursos oferecidos pela UAB. Consequentemente se a estrutura do curso é diferente, o papel do tutor, chamado de Orientador de Disciplina também é distinto dos demais cursos. Assim passaremos a descrever a atuação deste tutor no desenvolvimento deste curso.

\section{O papel da tutoria no curso semipresencial}

O papel do tutor nos cursos a distancia é fundamental. Quase toda a bibliografia ${ }^{1}$ sobre a educação a distância aponta essa função como primordial para o desenvolvimento desta modalidade de ensino.

Entretanto, com o desenvolvimento cada vez mais acelerado dessa modalidade de ensino, a utilização deste profissional cada vez mais é colocada em xeque, como nos aponta as professoras Gellati e Preamor:

A tutoria em Educação a Distância consiste num tema conceitual bastante polêmico e ainda carente de uma fundamentação legislativa que dê suporte administrativo, econômico e educacional e reconhecimento social de sua função no mercado de trabalho. Quando referimo-nos ao "tutor" ao seu papel, as suas funções, as suas tarefas e responsabilidades, ao seu lugar dentro dos processos de ensino e de aprendizagem na e para a educação a distância - muitos questionamentos surgem diante da diversidade de concepções e práticas que este recurso humano assume nos mais diferentes contextos de EAD: O que se quer dizer com ser "tutor"? Qual é a sua importância na modalidade de educação a distância? Que perfil de tutor é desejado em cursos em EAD? Até onde compreende as suas funções? Que espaços ele ocupa? Qual é a especificidade de seu papel? Que diferenças — se elas existem — o seu trabalho apresenta do ser professor em EAD? Como se forma um tutor? Como se avalia a sua produção? Que elementos e estratégias terá um bom projeto de tutoria? (GELLATI E PREAMOR, 2009, pág. 225)

Ou seja, dessas questões apontadas por Gellati e Preamor, outros estudos vêem na tutoria um processo de proletarização ou desqualificação do trabalho docente, pois o tutor,

\footnotetext{
${ }^{1}$ Ver BELLONI, 1999, 2002; PRETI, 1996; SANTOS, 2012; ZUN, 2006; JESUS, 2011
} 
atua como "professor", mas não é reconhecido como tal e consequentemente tem piores condições de trabalho, em especial salarial (ALONSO, 2010).

Estes diferentes focos de análise do papel do tutor vêm de encontro a os diferentes conceitos do tutor. Vejamos dois exemplos diferentes de conceitos de tutor:

O tutor é um facilitador, que ajuda o estudante a compreender os objetivos do curso. O tutor tornase um observador que reflete constantemente junto ao aluno a sua possível trajetória acadêmica, é um conselheiro e também um psicólogo, capaz de compreender as questões e as dificuldades do aprendiz e de ajudá-lo a responder de maneira adequada. É também um especialista em avaliação formativa e administrador para dar conta de certas exigências da instituição. (SILVA, 2008, pág. 47)

No mesmo artigo Silva cita o conceito de Lázaro e Asensi do que é ser tutor:

ser tutor é ser professor que se encarrega de atender diversos aspectos que não são tratados nas aulas. O tutor também é o professor, o educador integral de um grupo de alunos. A tutoria é uma atividade inerente à função do professor, que se realiza individual e coletivamente com os alunos em sala de aula a fim de facilitar a integração pessoal nos processos de aprendizagem; é a ação de ajuda ou orientação ao aluno que o professor-tutor pode realizar além de sua própria ação docente e paralelamente a ela. (SILVA, 2008, pág. 37)

Temos nestes dois conceitos sobre o que é tutor, as contradições, ora encarado como professor, ora como um facilitador das aprendizagens. Ou seja, pensar em apenas uma definição única sobre o papel do tutor é muito difícil, pois cada curso apresenta suas especificidades, que acabam moldando a atuação do tutor.

Desta forma, preferimos adotar a definição descrita por Schlosser em seu artigo citando Arnaiz “o professor-tutor é um profissional de ensino que atua como orientador da aprendizagem, um dinamizador da via socioafetiva, orientador pessoal, escolar e profissional dos alunos (2010, pág. 7). Entendemos que essa definição abarca melhor o trabalho do tutor, chamado de Orientador de Disciplina, no curso semipresencial de Pedagogia da UNESP/UNIVESP, já que a atuação deste não está restrito apenas ao Ambiente de Virtual de Aprendizagem (AVA), e também na condução semanal dos encontros presenciais. Ou seja, a relação entre tutor e aluno é muito direta e constante.

Essa concepção do tutor como o Orientador de aprendizagem, também já estava presente em outro projeto desenvolvido pela UNESP, no período de 2002 a 2007, denominado Pedagogia Cidadã (DAVID, 2007), que tinha a finalidade de formação superior em Pedagogia para os professores que atuação na rede pública sem esta formação. Neste 
projeto a figura do tutor, chamado de Professor Orientador, tinha funções semelhantes as desenvolvidas pelo Orientador de Disciplina no Curso de Pedagogia UNESP/UNIVESP.

$\mathrm{Na}$ análise daquele projeto, o professor Sebastião de Souza Lemes, descreve muito bem a importância da Mediação na construção da aprendizagem:

\begin{abstract}
Apesar de o material ser preparado e encaminhado aos grupos, a mediação necessário entre o material produzido (em termos de conteúdos), os procedimentos adotados e os objetivos estabelecidos para ele. Essa mediação deve possibilitar uma dinâmica eficiente que vise a consecução dos objetivos propostos. Assim a caracterização adequada do professor no âmbito deste processo é a de Mediador. Este tem um perfil mais próximo do docente que o Tutor, mas cumpre esses diferentes, mas complementares, papéis. Nessa tarefa, a principal função deste profissional é a regulação que desempenha além de todos os outros. Ao Mediador cabe desenvolver, principalmente o saber analisar, construir transversalidades e equipar o olhar sobre a realidade" (LEMES, 2007, pág. 84).
\end{abstract}

Pode-se perceber que as funções do tutor, em especial no curso de Pedagogia da UNESP/UNIVESP, carrega também esta característica da Mediação, do conhecimento, pois independente de todas as orientações pré-estabelecidas pela Coordenação Pedagógica do curso, a aprendizagem dar-se-á no momento da relação direta entre o tutor e o aluno e para isto diferentes habilidades para a realização desta mediação/orientação da aprendizagem são requisitadas.

Neste sentido, o Orientador de Disciplina tem que apresentar uma série de qualificações para o exercício da sua função (pedagógicas, técnicas, sociais e gerencias) como descreve Jesus (2011) em seu artigo. Vejamos cada uma dessas características:

Função pedagógica - o tutor tendo domínio do conteúdo pedagógico fomenta um ambiente social, amigável, essencial à aprendizagem online. Auxilia os alunos a caminharem por uma estrutura flexível, explorando não só os materiais do curso como também buscando outras fontes e estabelecendo debates (JESUS, 2011,pág. 7)

Função social - o tutor tem um grande desafio: criar um ambiente que estimule e favoreça a aprendizagem. ... o aluno poderá permanecer motivado durante o curso, sentir que tem alguém que prima por sua aprendizagem nas diferentes tarefas a serem realizadas (op. cit, pág.8)

Função gerencial - a função exige o gerenciamento de fóruns e chats, mediando discussões e garantido o bom andamento do curso. Sendo assim, o tutor deve estabelecer vinculo entre alunos e instituição, informando, determinando diretrizes, negociando regras, resolvendo questões relacionadas ao curso e avaliando resultados (op. cit. pág. 8)

Função técnica- esta função diz respeito ao conhecimento e ao uso da tecnologia... é importante que o tutor domine os fundamentos essenciais para fazer melhor uso que as tecnologias podem proporcionar para os processo de ensino e aprendizagem (pág. 9). 
Podemos então agora, caracterizar melhor a função do Orientador de Disciplina (tutor) na estrutura do curso semipresencial de pedagogia da UNESP/UNIVESP. Lembramos que a descrição deste artigo refere-se à atuação do Orientador de Disciplina, em um polo específico na cidade de São Paulo. Devemos deixar claro que em cada polo os orientadores tinham autonomia na condução de seu trabalho, quer seja ele virtual ou presencial. Entretanto, obrigatoriamente todos tinham um cronograma que deveria ser seguido com discussões dos textos, aplicação das atividades, aplicação das provas e fechamento das notas. Apenas na condução, ou melhor, na ação pedagógica cada orientador estabelecia a sua dinâmica.

Basicamente podemos dividir o trabalho do Orientador de Disciplina (tutor) em dois momentos: presencialmente e virtualmente. Analisaremos inicialmente as atividades presenciais, nos encontros com os alunos, que ocorriam duas vezes por semana, sempre as segundas e quintas-feiras. Inicialmente, o Orientador de Disciplina, tem que conduzir a discussão das leituras sugeridas no caderno de formação do aluno. Estas discussões podem ou não vir precedida de um vídeo produzido pela TV UNIVESP. Este processo de discussão do texto, durante todo o curso foi organizado de diferentes maneiras: leituras em grupo, leituras individuais, apresentação de seminários, apresentação através do Orientador de Disciplina, participação de palestrantes (da própria UNESP ou de ouras instituições), atividades culturais como cinema e teatro, etc. Ou seja, a dinâmica do encontro presencial sempre foi variada, visando a motivação dos alunos. Após estas discussões partia-se para a realização e orientação das atividades propostas pelos professores autores. Estes exercícios deveriam ser postados no AVA, sempre aos domingos, ou seja, no encontro presencial realizava-se apenas a orientação das atividades.

Com isto um dos problemas do ensino a distância que é dentro do AVA criar "ambientes de ensino interessantes e estimulantes a partir de programas e processos predominantemente textuais" (JESUS, 2011, pág. 2) ficou de certa forma superado, pois nos encontros presenciais estes textos eram discutidos de diferentes formas, e depois debatidos no AVA, seja através de fóruns ou de atividades individuais e coletivas.

Já com relação ao trabalho virtual do Orientador de Disciplina, cabia a este a correção e a orientação das atividades propostas, o encaminhamento e aprofundamento das discussões nos fóruns e estabelecer o contato com os alunos através das ferramentas: correio ou fórum. Era englobado também neste trabalho virtual, o diálogo entre Professor Autor, 
Coordenação Pedagógica e de Mídias, estabelecido pelo AVA. Desta forma, foi possível criar uma rede de comunicação entre os 21 polos, onde os que Orientadores podiam trocar informações, materiais e combinar atividades conjuntamente.

Com a descrição das atividades acima mencionadas podemos perceber que o orientador de disciplina tem que mobilizar uma série de capacidades pedagógicas, sociais, gerenciais e técnicas. Com isto temos a clareza de que o papel deste profissional foi fundamental para o desenvolvimento do curso. Assim todo o processo da ação pedagógica ficou quase que exclusivamente com os Orientadores de Disciplinas.

Entretanto, um dos desafios que muitos autores estudiosos, em especial, Belloni aponta para a Educação como um todo é a seguinte:

questão fundamental não está tanto na modalidade do ensino oferecido - se em presença ou a distância, a convergência dos dois paradigmas sendo a tendência mais evidente - mas sobretudo na capacidade de os sistemas ensinantes inovarem quanto aos conteúdos e às metodologias de ensino, de inventarem novas soluções para os problemas antigos e também para aqueles problemas novíssimos gerados pelo avanço técnico nos processos de informação e comunicação, especialmente aqueles relacionados com as novas formas de aprender (BELLONI,2002, pág. 139)

Ou seja, o papel do Orientador de Disciplina não se limitava apenas à função de um mero transmissor das propostas do Professor Autor, possibilitava também a autonomia para desenvolver uma prática ensino, em que aluno e tutor aprendiam conjuntamente. Neste processo de ensino e aprendizagem, desenvolvido no curso de Pedagogia da UNESP/UNIVESP compartilhamos da visão de Antonio Zuin:

\footnotetext{
O tutor não pode simplesmente absorver os conhecimentos transmitidos pelos professores, quer seja nos encontros presenciais esporádicos entre ambos, quer seja no sortilégio que as imagens de tais mestres "virtuais" possam exercer. Ele deve se permitir, cada vez mais, ousar saber, o que implica não a aceitação passiva dos conhecimentos obtidos, mas sim o questionamento destes mesmos conhecimentos. (ZUIN, 2006, pág. 949)
}

Na mesma direção, compreendemos que atuação do Orientador de Disciplina buscou seguir as lições do educador Paulo Freire (2009), visando desenvolver uma prática dialogicizante, em que o aluno e tutor compartilhavam conhecimento. Como todos os alunos eram efetivamente professores na prática os diferentes contextos escolares, da educação infantil, do ensino fundamental e médio, eram apresentados e discutidos durante os encontros presenciais possibilitando uma prática dialogicizante. 
Com isto, tivemos uma prática de ensino em que podemos realmente pensar as questões teóricas a partir das práticas adotadas em sala de aula, utilizando a leitura de textos ou assistindo aos vídeos produzidos pela TV UNIVESP, que exemplificavam contextos escolares de diversas regiões do Estado de São Paulo, e algumas experiências do exterior ou de outros estados brasileiros. Porém, a principal ferramenta desta prática foi o diálogo constante entre os alunos.

Os encontros presenciais, conduzidos pelo Orientador de Disciplina, foram fundamentais para a formação do aluno, principalmente devido a esta prática de formação dialogicizante. Não existia a figura do professor e sim sujeitos para discutirem o contexto escolar.

Neste sentido novamente Zuin nos expõe a importância dos encontros presenciais na Educação a distância:

\footnotetext{
Não por acaso, os programas de educação a distância que obtiveram resultados positivos foram aqueles que tiveram êxito de aproximar, presencialmente, os agentes educacionais por meio das mediações técnicas.... A necessidade do encontro presencial desvela aquela privação que foi distinguida anteriormente e que, na verdade, pode ser identificada como a força que impulsiona os indivíduos a desenvolver a tecnologia que os capacite a se aproximar de modo efetivo. (ZUIN, 2006, pág. 949-950)
}

Verificamos que o ensino a distância, necessita e precisa de uma aproximação entre os sujeitos, para isto os recursos tecnológicos e midiáticos são fundamentais, exemplo disto a entrevista de apresentação e encerramento da disciplina pelo professor Autor (esta entrevista era realizada nos estúdio da TV Cultura e apresentadas ao vivo durante os encontros presenciais) possibilitando a interação deste sujeito com o aluno. Outro mecanismo utilizado para esta interação foi o uso da sala virtual, também durante os encontros presenciais, onde os alunos faziam perguntas para o Professor Autor.

Podemos perceber que através desta organização que no curso semipresencial em Pedagogia o distanciamento entre os atores - aluno, tutor e Professor Autor - questão muito criticada nos estudos sobre a EAD- não faziam parte desse curso, mas ao contrário toda a dinâmica foi para a aproximação do aluno com o Professor Autor e com os Orientadores de Disciplina e Turma, esse último atuando diretamente com o aluno nas orientações dos TCC em encontros presenciais e via AVA.

Entretanto, este modelo de organização do curso apresenta um problema com relação ao uso do AVA, pois se em contrapartida a distância entre aluno/professor foi 
superada, com os encontros presenciais, a plataforma acabou sendo subutilizada, pois todas as dúvidas eram resolvidas nos encontros. Entendemos que de certa forma o AVA, tornou-se um depositório das atividades desenvolvidas e discutidas nos encontros presenciais. Foram poucos os alunos que utilizaram as ferramentas do AVA para trocar experiências e organizar suas atividades. Apenas durante os fóruns, que foram avaliativos, o AVA era amplamente utilizada pelos alunos.

Em contrapartida, para o Orientador de Disciplina o AVA era fundamental para o seu trabalho. Todas as correções e feedbacks aos alunos eram realizados na plataforma. A ferramenta correio foi utilizada para todo tido de orientação desde a pedagógica a gerencial, informando datas e horários de provas, atividades, etc. Esta ferramenta correio foi extremamente importante para incentivar e orientar os alunos, muitas vezes sendo utilizada como objeto motivacional.

Da mesma forma, toda a comunicação com a equipe coordenadora do curso, bem como com os Professores Autores era realizada via AVA. Consequentemente o acesso pelo tutor tinha que ser diário para tomar conhecimento de todas as ações que estavam ocorrendo durante o desenvolvimento do curso.

Conforme, esta descrição podemos perceber que o Orientador de Disciplina, durante todo o curso tinha que mobilizar todas as suas capacidades, como descrito anteriormente (JESUS, 2011) para que a ação pedagógica realmente se concretizasse nesta modalidade de ensino semipresencial.

\section{Considerações Finais}

A educação a distância apresenta-se como uma modalidade de ensino que pode ser vista como um mecanismo para ampliação das ofertas de vagas no ensino superior ou para promover a formação continuada. O curso semipresencial de Pedagogia da UNESP/UNIVESP tem estas duas características, pois permitiu que muitos professores sem formação superior conseguissem a formação adequada para a atuação no magistério e possibilitou a formação continuada do professor anteriormente graduado.

Durante esse processo, como destacamos neste artigo, o papel do tutor, chamado de Orientador de Disciplina, foi fundamental para o desenvolvimento do curso. Podemos perceber que quase toda a ação pedagógica ficou a cargo deste ator. Com isto o 
Orientador de Disciplina mobilizou diversas capacidades e habilidades para atingir o objetivo do curso que foi a formação de qualidade para esses alunos.

Por fim, queremos destacar que o modelo de curso semipresencial contribuiu para reduzir a evasão dos alunos em um curso na modalidade EAD de cerca 55\%, para uma média de 26\% (RIGUETTO, 2013). Entendemos que um dos fatores responsável por isso, foi a atuação dos Orientadores de Disciplina foram eles que comandaram todo o processo de aprendizagem presencial e a distância, diferenciando-se de outros modelos de EAD, como por exemplo, o da Universidade Aberta do Brasil (UAB), em que dois tutores um presencial e outro a distância atuam, mas que muitas vezes não existe um diálogo entre eles. Além disso, os encontros presenciais acontecem somente para a realização de provas. Neste artigo podemos perceber que existem outras formas de atuar com a educação a distância que permitem a superação do preconceito em relação a essa modalidade e comprovando a possibilidade de um ensino de excelência e qualidade.

\section{Bibliografia}

ALONSO, K.M. A educação a distância no Brasil: a busca de identidade. In: PRETI, O.

(Org.). Educação a distância: inícios e indícios de um percurso. Cuiabá:

NEAD/UFMT, 1996. p. 57-74

BELLONI, Maria Luiza.Ensaio sobre a educação a distância no Brasil. Educação e Sociedade [online]. $2002, \quad$ vol.23, n.78, pp. 117-142. ISSN 0101-7330. http://dx.doi.org/10.1590/S0101-73302002000200008. acesso em 11 de setembro de 2013.

DAVID, Célia Maria. Organização do Curso de Pedagogia do programa Pedagogia Cidadã. In: PALMA FILHO, J. C. (org.) Pedagogia Cidadã: uma nova prática na formação do educador. São Paulo: Unesp. Pró-Reitoria de graduação/Rettec Artes Gráficas, 2007.

FREIRE, Paulo. Pedagogia da autonomia: saberes necessários à prática educativa. São Paulo: Paz e Terra, 2009.

GELATTI, Lilian Schwab e PREMAOR, Vânia Ben. Auto-avaliação da atuação da tutoria no curso de licenciatura em pedagogia a distância de uma universidade brasileira. Revista $\begin{array}{lllll}\text { Portuguesa de } & \text { Educação } & \text { [On-line] }\end{array}$ em:<http://www.redalyc.org/articulo.oa?id=37412031010> ISSN 0871-9187 acesso 13 de setembro de 2013

JESUS, Ana Maria Ribas. A tutoria em ambiente de EAD. IN. VI Encontro Nacional de Hipertexto e tecnologias Educacionais. Universidade de Sorocaba, 26 e 27 de setembro 
de 2011. Disponível em http://www.uniso.br/ead/hipertexto/anais/08_AnaRibas2.pdf acesso 10 de setembro de 2013.

LEMES, Sebastião de Douza. Considerações acerca da estrutura e metodologia da Pedagogia Cidadã. In: PALMA FILHO, J. C. (org.) Pedagogia Cidadã: uma nova prática na formação do educador. São Paulo: Unesp. Pró-Reitoria de graduação/Rettec Artes Gráficas, 2007.

PRETI, Oreste. Educação a distância: uma prática educativa mediadora e mediatizada. IN. PRETI, Oreste (Org.). Educação a distância: inícios e indícios de um percurso. Cuiabá: UFMT, Núcleo de Educação Aberta e a Distância, 1996.

RIGHETTI, Sabine. "Curso de pedagogia a distância cresce 45 vezes em dez anos” In Folha de São Paulo online, 04/08/2013. Disponível em http://www1.folha.uol.com.br/educacao/2013/08/1321247-curso-de-pedagogia-adistancia-cresce-45-vezes-em-dez-anos.shtml. Acesso em 21 de setembro de 2013.

SANTOS, Daniela. Revisão da Literatura: educação a distância. janeiro 2008. Disponível em http://www.administradores.com.br/mobile/artigos/economia-e-financas/revisao-daliteratura-educacao-a-distancia/20823/ acesso em 04 de setembro de 2013.

SCHOLSSOR, Rejane Leal. A atuação dos tutores nos cursos de educação a distância IN. Colabor@- Revista Digital da CVA-Ricesu, volume 6, numero 22, fevereiro de 201. Disponível em http://pead.ucpel.tche.br/revistas/index.php/colabora/article/view/128/112

SILVA, Marinilson Barbosa. O processo de construção de identidades individuais e coletivas do ser-tutor no contexto da educação a distância. Tese de doutoradoUFRGS, Porto Alegre, 2008. Disponível em http://www.lume.ufrgs.br/bitstream/handle/10183/15341/000671437.pdf?sequence=1 acesso 10 de setembro de 2013.

UAB (UNIVERSIDADE ABERTA DO BRASIL). "Histórico da UAB". Disponível em http://www.uab.capes.gov.br/index.php?option=com_content\&view=article\&id=9:histori co-\&catid=6:sobre \&Itemid=21 (acesso 11 de setembro de 2013)

UNESP/UNIVESP. Manual Acadêmico do curso de Pedagogia: programa de formação de professores em exercício para a educação infantil, para séries iniciais do ensino fundamental e para a gestão da unidade escolar. São Paulo: Editora Cultura Acadêmica, 2010 .

ZUIN, Antonio A. S..Educação a distância ou educação distante? O Programa Universidade Aberta do Brasil, o tutor e o professor virtual. Educação e Sociedade [online]. 2006, vol.27, n.96, pp. 935-954. ISSN 0101-7330. http://dx.doi.org/10.1590/S010173302006000300014 . Acesso em 17 de setembro de 2013. 